\title{
PRIMARY EWING'S SARCOMA OF THE SPINE
}

\section{Case report}

\author{
Leandro I. Dini', Rodrigo Mendonça², Pasquale Gallo³
}

\begin{abstract}
Primary malignant sarcomas of the spine are extremely rare. Because of biological heterogeneity, these tumors have variable sensitivity to radiation and chemotherapy. Adequate local control through complete tumor removal is an important therapeutic goal. However, aggressive resection of tumors in the spinal column must be coupled with restoration of spinal column stability and minimization of neural deficits. The balance of these factors makes treatment of primary sarcomas of the spine challenging, and dictates an individual approach to treatment. We report on a 18 years old man with primary Ewing's s a rcoma of the nonsacral spine. The clinical picture and imaging characteristics were analyzed as well as the management modalities and outcome.
\end{abstract}

KEY WORDS: Ewing's sarcoma, primary spine tumor, spine stabilization.

\section{Sarcoma de Ewing primário da coluna vertebral: relato de caso}

RESUMO - Sarcomas malignos primários da coluna são extremamente raros. Devido sua heterogeneidade biológica, estes tumores apresentam sensibilidade variada à radioterapia e à quimioterapia.O controle local adequado através da ressecção tumoral completa é um objetivo terapêutico importante. Contudo, a ressecção completa dos tumores da coluna vertebral deve ser realizada com a restauração da estabilidade espinhal e minimização do déficit neurológico. $O$ equilíbrio entre estes fatores torna o tratamento dos sarcomas da coluna desafiador, exigindo-se uma abordagem individualizada para o tratamento de cada paciente. Relatamos um caso de sarcoma de Ewing da coluna não-sacral em um homem de 18 anos. 0 quadro clínico e características de imagem foram analisados, bem como a modalidades de manejo e o prognóstico.

PALAVRAS-CHAVE: sarcoma de Ewing, tumor espinhal, estabilização espinhal.

Primary malignant sarcomas of the spine are extremely rare. It has been estimated that they account for only $3.5 \%$ to $14.9 \%$ of all primary bone sarcomas $^{1-5}$. In the study of primary vertebral Ewing's sarcoma (ES), the division of the spine into nonsacral and sacral is important and is dictated by the different behavior of ES in these two regions in terms of response therapy and survival rates ${ }^{4}$. Most studies on ES involving the mobile spine are limited to case reports. A few larger series evaluated patients with primary ES affecting the mobile and nonmobile spine ${ }^{1,6-9}$. Microscopic examination demonstrates small, round blue cells with a uniform appearance. Electron microscopy, immunohistochemistry, and cytogenetic studies help differentiate ES from other small, round blue ceel tumors. The translocation $t(11 ; 22)(q 24 ; q 12)$ is identified in most cases of $\mathrm{ES}^{10}$. Adequate treatment of primary malignant spine tumors is aimed at cure rather than palliation whenever possible. The definitive management of Ewing's sarcoma of the spine, as in other locations, could include three main modalities: surgery, radiotherapy, and combination chemotheraphy ${ }^{1}$.

The purpose of the current study is to report the diagnosis and the treatment of primary sarcomas of the mobile spine.

\section{CASE}

A 18-year-old man presented with a 4-month history of prog ressively worsening back pain, and lower extremity weakness. No constitutional symptoms were present. Bladder dysfunction was presented at admission. Results of a physical examination disclosed bilateral paraspinal ten-

Serviço de Neuroci ru rgia do Hospital Centenário, São Leopoldo/RS, Brazil and Serviço de Neurociru rgia do Hospital Cristo Redentor, Porto Alegre/RS, Brazil: ${ }^{1} \mathrm{MD}$, Neurosurgeon; ${ }^{2} \mathrm{MD}$, Neurosurgery Resident; ${ }^{3} \mathrm{MD}$, Neurosurgery Preceptor.

Received 19 January 2006, received in final form 4 April 2006. Accepted 10 May 2006.

Dr. Rodrigo Mendonça - Serviço de Neurologia, Hospital Cristo Redentor - Rua Domingos Rubbo 20 / Sala 260 - $91040-200$ Porto Alegre RS - Brasil. 


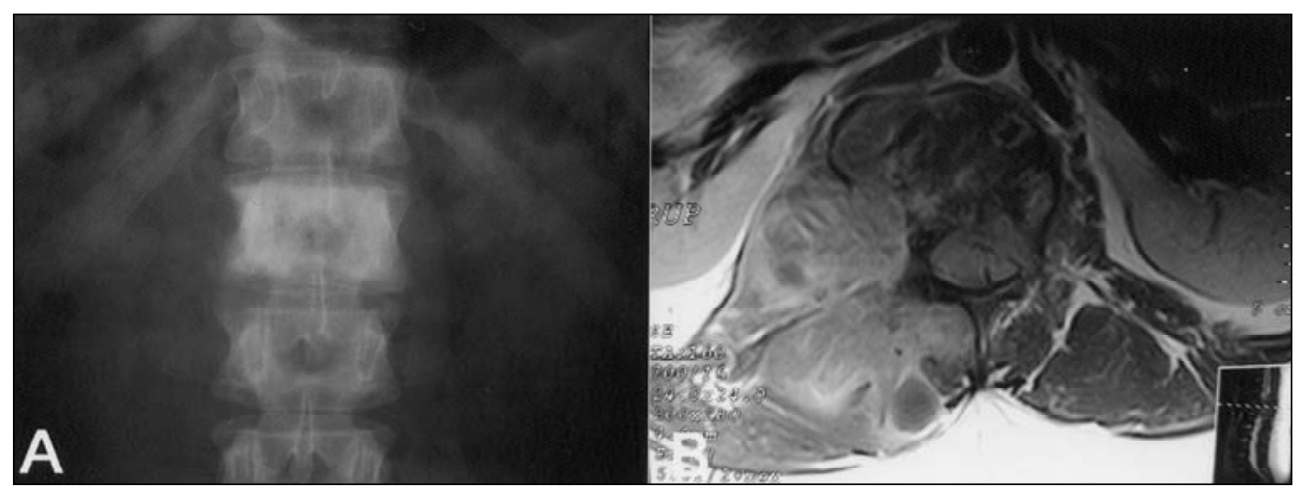

Fig 1. (A) Plain radiographs of the thoracolumbar spine revealed sclerotic $L 1$ vertebra. (B) Axial pro jection of T2 MRI image demonstrating tumor filling the spinal canal and invasion of right psoas muscle.

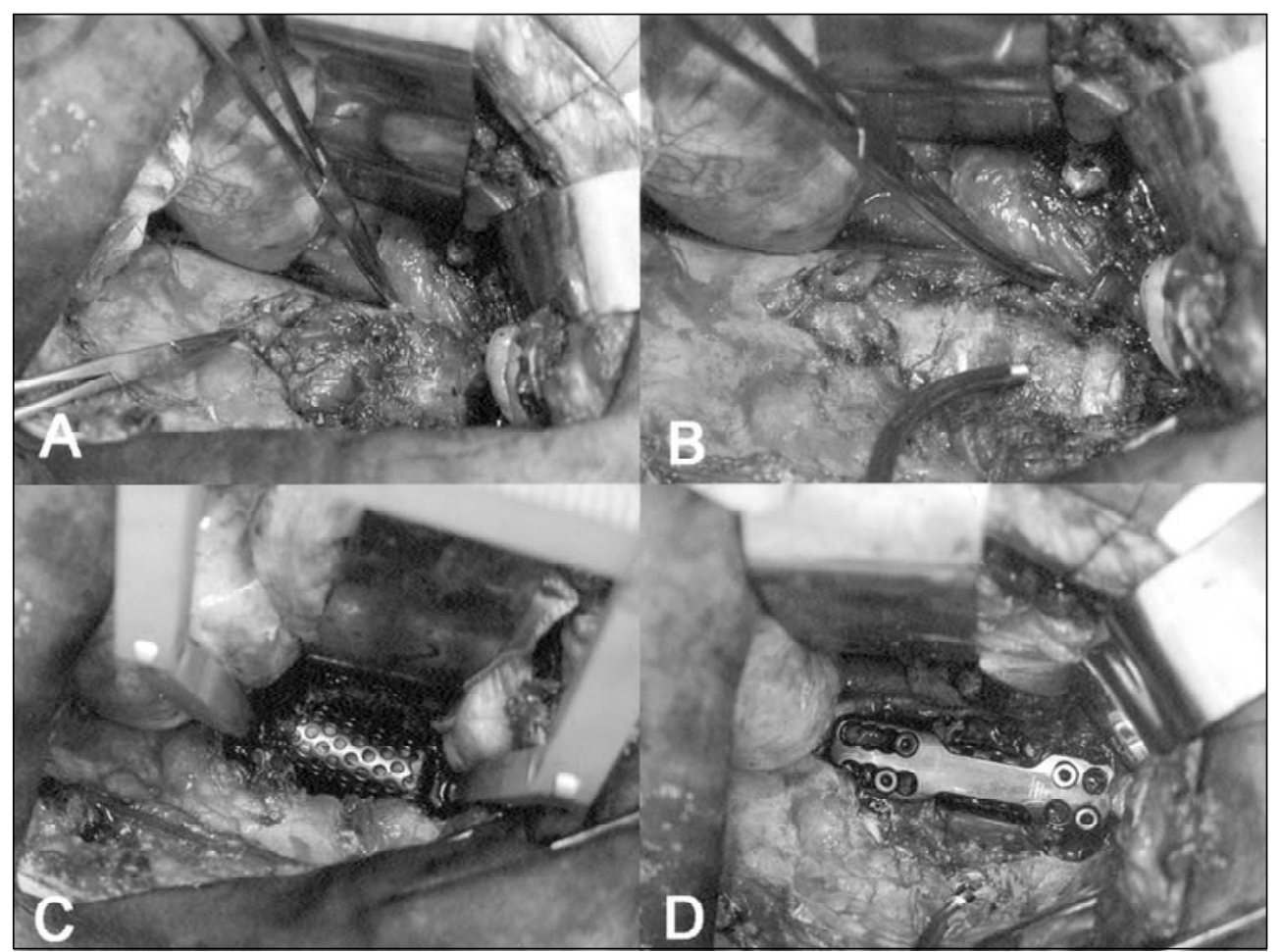

Fig 2. Anterior approach, intra-operative views. (A) Tumor invading the psoas muscle. (B) Excision of psoas, revealing a $L 1$ vertebra before corpectomy. (C) Titanium mesh cylinder filled with autolo gous rib. (D) Z-plate system fixed to T12 and L2 vertebrae, spinal canal decompressed.

dermess with lower extremity paraparesis (Frankel B). Sensibility was decreased below the level L1. The results of labor a to rystudies, including ery th rocyte sedimentation rate we re within normal limits. Plain radiographs of the thoracolumbar spine revealed sclerotic L1 vertebra. Computed tomographic (CT) and magnetic resonance imaging (MRI) evaluation of the patient showed a soft tissue mass invading the epidural space (Fig 1). The patient was without evidence of metastatic disease at presentation as determined by staging chest radiographs, chest computed tomography scans and bone scans.

The patient underwent surg ery as the first line of man- agement. Subtotal vertebrectomy and decompression was obtained with a combined anterior and posterior approach (Fig 2 and 3). Anterior reconstruction was carried out using a titanium mesh cage filled with autologous bone graft from resected rib (Fig $3 \mathrm{C}$ ). The patient had histologic confirmation of ES. Small, round blue cells with round to oval nuclei, uniformly packed into broad nests were identified (Fig 3D). Periodic acid-Schiff staining was performed to confirmthe presence of intracytoplasmic glycogen. The patient was administered chemotherapy (vincristine, actinomycin $\mathrm{D}$, cyclophosphamide, methotrexate) and additional radiotherapy to T12-L2 (total dose, $40 \mathrm{~Gy}$ ). 


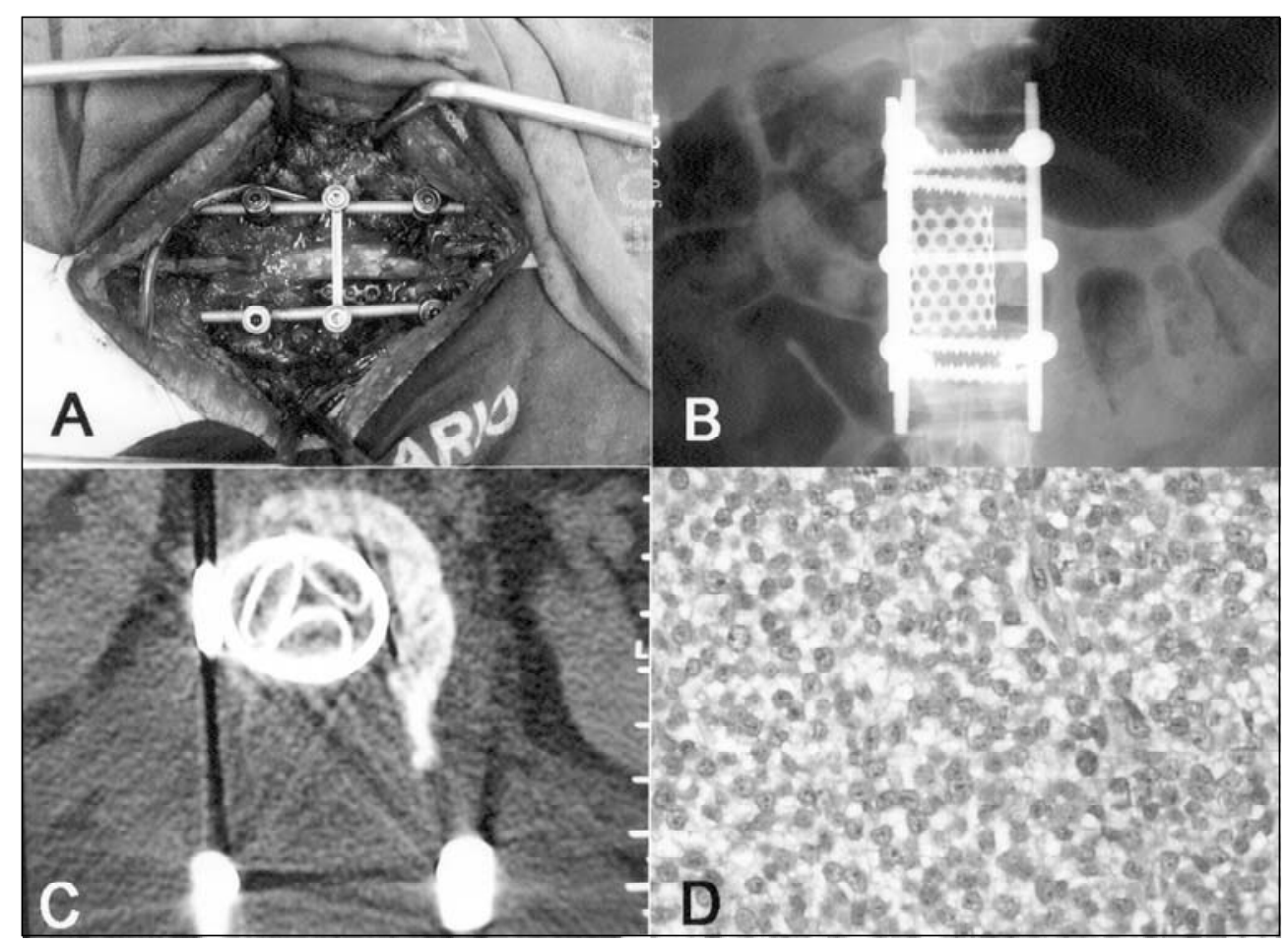

Fig 3. (A) Posterior approach, intra-operative view of pedicular screws, longitudibal bars and crosslink system. Note the titanium mesh cylinder anteriorly to the dural sac. (B) Postoperative plain radi ograph, showing circunferencial instrumentation. (C) Postoperative $C T$, showing the autologous rib inside the cylinder. $(D)$ Histologic examination of the specimen showed Ewing sarcoma. The tumor conformed to the histological criteria for ES. Hipercellular growths of small cells with round to oval nuclei, uniformly packed into broad nests, and focal areas of hemorrhage and necrosis.

The neurological outcome of surgery was judged good with mild residual deficits. Strength and sensibility in the lower extremities gradually increased, and within 3 months after the surgery, the patient was ambulatory.

The case report was done with the agreement of both the patient and the Ethical Committee of Hospital Centenário.

\section{DISCUSSION}

Primarysarcomas of the spinal column are difficult to classify as a clinical entity. The complex neuromusculoskeletal development of the spine may account for a spectrum of malignant tumors with distinct biological behaviors. The diff e rential diagnosis of a small round-cell bone tumor includes, in addition toes, ne u rdblastoma, primitive neuroectodermal tumor of bone (PNET), malignant lymphoma, and rhabdomyosarcoma. The differentiation between these tumors on basis of light histological data alone may not always be accurate. Current standards dictate that patients with a small round-cell bone tumor be evaluated, in addition to light microscopy and electron microscopy, by immunohistochemical and occasionnaly cytogenetic analysis ${ }^{11,12}$. Chromosomal data from ES reveals a remarkably consistent chromosomal anomaly, the reciproal translocation $t(11 ; 22)(q 24 ; q 12)^{10,13}$. Other numerical and/or structural changes have also been reported ${ }^{14,15}$. Although the diffe rentiation between other tumors based on histologic data alone may not always be accurate, the patient in this report satisfied the histologic criteria required to the diagnosis of ES.

The age at presentation ranged from 12 to 24 years (median, $21 \mathrm{yr})^{1}$. Ewing's sarcoma of the spine is a rare condition that appears with a clinical triad of local pain, neurological deficit, and palpable mass. Local back pain usually is the first symptom to occur. Even when initial plain film studies reveal no abnormality, the physician should be alert to the possibility of spinal malignancy, especially when the patient is in the first two decades of life and symptoms, including severe local pain, are not relieved by bed rest, and overlying point tenderness is present.

Plain radiographic signs of ES are late to appear, usually after the neurological signs have became obvious. The most common finding was lytic bone destruction involving the vertebra ${ }^{1}$. The lytic changes 
varied from focal lytic lesion, which is more common, to complete flattening of the vertebral body (vert ebra plana) ${ }^{16}$. Sclerotic changes are also rarely observed. $\mathrm{CT}$ is of great value in determining the extent of involvement of both the vertebral bodies and the posterior elements as well as in outlining the soft tissue component. CT-guided needle biopsy of vertebral or paravertebral lesions can be accomplished with accuracy and relative ease. MRI is very sensitive in the early detection of $E S$ in the spine ${ }^{17,18}$. MRI is superior for visualizing epidural compression and tumor spread to the bone marrow or extension into adjacent soft tissues. The relationship of tumor to adjacent vasculature can also be determinated. MRI may be of value in monitoring the effect of chemotherapy on bone sarcomas. MRI, enhanced with gadolinium diethylene-triamine-pentaaceti acid, showed the highest accuracy in determining the response to preoperative chemotherapy ${ }^{19}$. MRI may be of value in p reoperative planning for a reliable definition of the surgical margins of the tumor, which can permit safer and more complete resection.

ES is frequently multifocal. Skeletal scintigraphy before staging is an important step to rule out other foci and also it has been used in the follow-up treatment of primary $\mathrm{ES}^{20}$.

In the Intergroup Ewing's Sarcoma Study (IESS) experience, lesions of nonsacral spine had a $100 \%$ local contrd rate and an $86 \%$ long-term survival rate. Sac rococcygeal primary tumors responded more poorly (they usually are diagnosed at a more advanced stage and are more difficult to supply adequate irr a d iation to or to achieve total surgical excision of the sacral tumor) ${ }^{4,21}$. It is noteworthy that the good outcome reported by the IESS for ES of the nonsacral spine has not been duplicated in many cases reports ${ }^{1,22-24}$. The definitive treatment of ES should have two goals: local treatment of the primary tumor; maintence combination chemotherapy to eradicate systemic micrometastasis.

Because of biological heterogeneity, these tumors have variable sensitivity to radiation and chemotherapy ${ }^{25}$. The classical chemotherapy regimen in ES consists of either VAC-A, that consisted of four agents: vincristine sulfate, dactinomycin, cyclophosphamide and doxorubicin hydrochloride. Treatment consisted of four agents, VAC-A, administered once very 2 weeks for 18 months, or three agents, VAC, administered for 24 months. Other protocols have been used ${ }^{26-30}$.

It has been suggested that in a neurologically stable patient, initial chemotherapy after biopsy should be administered to shrink the primary tumor before definitive local treatment, be it surg e ry or radiotherapy, is instituted ${ }^{23,31,32}$. Preoperative chemotherapy o ffers three main advantages: bulky or unresectable tumors can be reduced in size and made respectable; early systemic chemotherapy can help eradicate circulating tumor cells and micro metastasis; and the information of the sensitivity of the tumor to the chemotherapy. The histological determinant of prognosis in ES is the histological grade of regression after combination chemotherapy ${ }^{33-36}$.

Initial chemotherapy has also been tried for acute relief of epidural compression ${ }^{31}$. Further clinical as well as experimental data are available in support of chemotherapy as the primary modality for epidural decompression in highly chemosensitive tumors ${ }^{37,38}$; however, the response of ES to initial chemotherapy is not universal $(61 \text { a } 67 \%)^{23}$. The use of multiagent chemotherapy combined with surg e ry and/or radiotherapy for definitive local control increased diseasefree survival rates to 50 to $80 \%^{39-41}$.

Current spinal resection and reconst ruction techniques may lead to improved oncologic and clinical outcomes. If the patient is neurologically stable and a tissue diagnosis is required then a large-bore-bore needle biopsy should be considered. Once the diagnosis of ES is confirmed, then chemotherapy can be administered. The soft tissue mass and spinal cord compression usually rapidly diminish. Tumor restaging studies are then performed. If there is no evidence of metastases, then an en bloc spondilectomy should be considered because the risk of local recurrence is lower and long-term survival may be improved compared with an intralesional excision or radiation therapy alone.

When there is epidural compression secondary to ES with rapidly prog ressing neurological symptoms or impending paralysis, prompt surgical intervention is the only primary alternative if irreversible deficit is to be prevented 1 . For tumors involving the anterior vertebral body, an anterior approach is the preferred route to prevent neurological damage and futurespinal instability. ES tends to invade the spinal canal from the paravertebral soft tissue component th raugh the intervertebral foramen, compressing the cord circumferentially. This makes laminectomy an e ffective approach for decompression. So, if the patient is not neurologically stable, then radical anterior decompression with reconstruction and stabilization and/or decompressive laminectomy with stabilization should be considered. Chemotherapy can then 
be administered, and definitive local control with radiation therapy should be considered ${ }^{42}$.

Marco et al. ${ }^{42}$ evaluated the oncological outcome of patients with nonmetastatic Ewing, s sarcoma of the mobile spine treated with systemic chemotherapy and radiation therapy for definitive local control. Ten of the thirteen studied patients had a decompressive laminectomy, but none of them had intralesional exision or bloc spondilectomy. The disease-free survival rate was $49 \%$ and $36 \%$ at 5 and 10 years. Four of the 10 patients $(40 \%)$ that had a laminectomy (without spinal instrumentation) developed sintomatic pro g ressive kyphosis. Decompressive laminectomy alone removes the posterior tension band, which can render the spinal column more unstable. The patient is thus at risk for anterior column collapse, and subsequent development of kyphosis and neurological demise. Spinal stabilization probably decreases the risk of kyphosis and should be considered. The combination of improved resection, stabilization, and fusion techniques allows for more aggressive removal of malignant spinal tumors with acceptable mortality and morbidity. There is a relationship between local control and overall survival. Most of deaths in the current series were attributable to complications from local recurrences ${ }^{43}$. Residual tumor at the margin, and resection in a piecemeal fashion result in higher recurrence rates that were associated with early mortality ${ }^{43}$. Therefore, the surgeon should attempt complete en bloc tumor resection whenever possible. Talac et al. ${ }^{43}$ analyzed the relationship between su rgical margins and local recu rrence in sarcomas of the spine in thirty patients. They concluded that en bloc resection with tumor-free margins provides substancial improvement in overall survival. The local recurrence rate for patients with a negative margin was $16.7 \%$. The method of tumor removal may have an important effect on local recurrence: an bloc resection was better than piecemeal resection. The rate of re c u rrence for patients with positive margins was $55.6 \%$.

The risk of local recurrence is probably lower for patients treated with an en bloc surgical excision with adequate margins ${ }^{44-46}$. Minimizing the risk of local recurrence is especially important around the spinal column because local recurrence can lead to neurological demise. The risk of local recurrence is probably higher with an intralesional excision compared with en bloc spondilectomy ${ }^{47}$. However, the advantage of this approach is that many spinal surgeons are familiar with the technique of intralesional excision, the spinal column remains more stable, and the pro- cedure is less demanding than en bloc spondilectomy techniques.

We can summarize the indications for surgery in ES of the spine as follows: epidural decompression in patients with neurological decompensation; stabilization for primary instability or for cases with extensive bony involvement by tumor where instability is likely to occur after tumor resection; poor response to initial treatment with chemotherapy or radiotherapy; residual disease.

The role of an intralesion excision combined with radiation therapy for patients with ES of spine is unclear. The lower survival rates reported with radiation therapy compared with surg e ry for local contro I may be related to residual nests of viable tumor within the radiated site. These residual nests of tumor are potencial sources of local recu rrence or distant relap$\mathrm{se}^{48}$. However, radiation therapy is generally more effective against microscopic disease that macroscopic tumor ${ }^{49-51}$.

Radiation doses for spinal tumors should not exceed the limit of cord tolerance ( $45 \mathrm{~Gy}$ ) to avoid the risk of radiation-induced myelophathy and seconda ry sarcomas ${ }^{1}$. The initial use of radiotherapy in patients with epidural compression and severe neurological symptoms will be complicated by edema, which could increase cord compression ${ }^{1}$. Larges doses of st e roids could result in improvement in the neuro logical deficit. Furtherm ore, lower doses of radiation a re commonly used to treat patients with microscopic residual tumors after an intralesional excision. A lower dose of radiation probably decreases the risk of developing a radiation-associated sarcoma or myelopathy. Radiosurgery may be a valuable option for recurrent spinal tumors ${ }^{52}$.

Adequate surgical treatment of primary malignant spine tumors involves wide or radical resection in combination with neoadjuvant chemotherapy and, if responsive, radiotherapy. The aim of preoperative chemotherapy is to reduce the viable tumor mass and to prevent further dissemination. The combination of systemic and surgical treatment offers the patient a good chance of survival with a satisfactory quality of life.

\section{REFERENCES}

1. Sharafuddin MJ, Haddad FS, Hitchon PW, et al. Treatment options in primary Ewing's sarcoma of the spine: report of seven cases and review of the literature. Neurosurgery 1992;30:610-618.

2. Bacci G, Picci P, Gherlinzoni F, et al. Localized Ewing's sarcoma of bone: ten year's experience at the Instituto Ortopedico Rizzoli in 124 cases treated with multimodal therapy. Eur J Cancer Clin Oncol 1985;21: 163-173. 
3. Klaassen MA, Hoffman G. Ewing's sarcoma presenting as spondylolisthesis. Report of a case. J Bone Joint Surg 1987;69:1089-1092.

4. Pilepich MV, Vietti TJ, Nesbit ME, et al. Ewing's sarcoma of the vertebral column. Int J Radiat Oncol Biol Phys 1981;7:27-31.

5. Wilkins RM, Pritchard DJ, Burgert EO, Unni KK. Ewing's sarcoma of bone: experience with 140 patients. Cancer 1986;58:2551-2555.

6. Barbieri E, Frezza G, Martelli O, et al. Non conventional fractionation in radiotherapy of the musculo-skeletal sarcomas. Tumori 1998;84: 167-170.

7. G rubb MR, Currier BL, Pritchard DJ, et al. Primary Ewing's sarcoma of the spine. Spine 1994;19:309-313.

8. Pilepich MV, Vietti TJ, Nesbit ME, et al. Ewing's sarcoma of the vertebral column. Int J Radiat Oncol Biol Phys 1981;7:27-31.

9. Venkateswaran L, Rodriguez-Galindo C, Merchant TE, et al. Primary Ewing tumor of the vertebrae: clinical characteristics, prognostic factors and outcome. Med Pediatr Oncol 2001;37:30-35.

10. Turc-Carel C, Philip I, Berger MP, et al. Chromosome study of Ewing's sarcoma (ES) cell lines: consistency of a reciprocal translocation $t(11 ; 22)$ (q24;q12). Cancer Genet Cytogenet 1984;12:1-19.

11. Schmidt D, Harms D, Pilon VA. Small-cell pediatric tumors: Histology, immunohistochemistry, and electron microscopy. Clin Lab Med 1987;7:63-89.

12. Triche TJ. Diagnosis of small round cell tumors of childhood. Bull Cancer (Paris) 1988;75:297-310.

13. Turc-Card C, Aurias A, Mugneret F, et al. Chromosomes in Ewing's sa rcoma: I. An evaluation of 85 cases of remarkable consistency of t(11;22)(q24;q12). Cancer Genet Cytogenet 1988;32:229-238.

14. Douglass EC, Rowe ST, Valentine M, Parham D, Meyer WH, Thompson EI. A second nonrandom translocation, der $(16) \mathrm{t}(1 ; 16)(\mathrm{q} 21 ; \mathrm{q} 13)$, in Ewing's sarcoma and peripheral neuroectodermal tumor. Cytogenet Cell Genet 1990;53:87-90.

15. Mugneret F, Lizard S, Aurias A, Turc-Carel C. Chromosomes in Ewing's sarcoma: II. Nonrandom additional changes, trisomy 8 and der (16) $\mathrm{t}$ (1;16). Cancer Genet Cytogenet 1988;32:239-245.

16. Papagelopoulos PJ, Currier BL, Galanis E, et al. Vertebra plana caused by primary Ewing sarcoma: case report and review of the literature. J Spinal Disord Techni 2002;15:252-257.

17. Markisz JA, Bottger BA, Bullough P, Knowles RJR, Whalen JP, Cahil PT. The role of MRI in the diagnosis and evaluation of bone diseases. Presented at the Fourth Annual Meeting of the Society of Magnetic Resonance in Medicine. Book of Abstracts, 1, 985:1176.

18. Vanel D, Couanet D, Leclere J, Patte C. Early detection of bone metastases of Ewing's sarcoma by magnetic resonance imaging. Diag Imaging Clin Med 1986;55:381-383.

19. Erlmann R, Sciuk J, Bosse A, Ritter J, Kusnierz-Glaz CR. Response of osteosaroma and Ewing's sarcoma to preoperative chemotherapy: assessment with dynamic and static MR imaging and skeletal scintigraphy. Radiology 1990;175:791-796.

20. Estes DN, Magill HL, Thompson EI, Hayes FA. Primary Ewing's sarcoma: follow-up with Ga-67 scintigraphy. Radiology 1990;177:449-453.

21. Weir JC, Amonett MR, Krolls SO. Tu mo rous conditions of the fibula, supraorbital area and mandible. J Oral Pathol 1979;8:313-318.

22. Whitehouse GH, Griffiths GJ. Roentgenologic aspects of spinal involvement by primary and metastatic Ewing's tumor. J Can Assoc Radiol 1976;27:290-297.

23. Oberlin O, Patte C, Demeocq F, et al. The response to initial chemotherapy as a prognostic factor in localized Ewing's sarcoma. Eur J Cancer Clin Oncol 1985;21:463-467.

24. Siegal GP, Oliver WR, Reinus WR, et al. Primary Ewing's sarcoma involving the bones of the head and neck. Cancer 1987;60:2829-2840.

25. B ruckner JD, Conrad III EU. Spine. In Simon MA, Springfield D (eds). Surgery for bone and soft-tissue tumors. Philadelphia: Lippincott-Raven 1998:435-450.

26. Bu rgert EO Jr, Nesbit ME Jr, Garnsey LA, et al. Multimodal therapy for the management of nonpelvic, localized Ewing's sarcoma of bone: Intergroup study IESS-II. J Clin Oncol 1990;8:1514-1524.

27. Hayes FA, Thompson EI, Hustu HO, Kumar M, Coburn T, Webber B.
The response of Ewing's sarcoma to sequential cyclophosphamide and adriamycin induction therapy. J Clin Oncol 1983;1:45-51.

28. Miser JS, Kinsella TJ, Triche TJ, et al. Preliminary results of treatment of Ewing's sarcoma of bone in children and young adults: Six months of intensive combined modality chemotherapy without maintenance. J Clin Oncol 1988;6:484-490.

29. Zalupski M, Baker LH. Ifosfamide. J Natl Cancer Inst 1988;80:556-566.

30. O'Dwyer PJ, Leyland-Jones B, Alonso T, Marsoni S, Wittes R. Etoposide (VP-16-213): current status of an active cancer drug. N Engl J Med 1985; 312:692-700.

31. Hayes FA, Thompson EI, Hvizdala E, O'Connor D, Green AA. Chemotherapy as an alternative to laminectomy and radiation in the management of epidural tumor. J Pediatr 1984;104:221-224.

32. Jurgens H, Donaldson SS, Gobel U. Ewing's sarcoma. In Voute PA, Bar ret A, Bloom HJG, Lemerle J, Neidhardt MK (eds). Cancer in children: clinical management. New York: Springer-Verlag, 1986:300-315.

33. Sund a resan N, Rosen G, Fortner JG, Lane JM, Hilaris BS. Preoperative chemotherapy and surgical resection in the management of posterior paraspinal tumors: report of three cases. J Neuro su rg1983;58:446-450.

34. Ju rgens H, Exner J, Gadner H, et al. Multidisciplinary treatment of primary Ewing's sarcoma of bone: a 6-year experience of a European cooperative trial. Cancer 1988;61:23-32.

35. Rosen G, Marcove RC, Caparros B, Niremberg A, Kosloff C, Huvos AG. The rationale for preoperative chemotherapy and delayed surgery. Cancer 1979;43:2163-2177.

36. Salzer-Kuntschik M, Delling D, Beron G, Sigmund R. Morphological grades of reg ression of osteosarcoma after polychemotherapy: Study COSS 80. J Cancer Res Clin Oncol 1983;106:21-24.

37. King D, Goodman J, Hawk T, Boles ET Jr, Sayers MP. Dumbbell neuroblastomas in children. Arch Surg 1975;10:888-891.

38. Traggis D, Filler R, Druckman H, Jaffe N, Cassady JR. Prognosis for children presenting with paralysis. J Pediatr Surg 1977;12:419-421.

39. Nesbit ME Jr, Gehan EA, Burgert EO Jr, et al. Multimodal therapy for the management of primary, nonmetastatic Ewing's sarcoma of bone: a long-term follow-up of the First Interg roup study. J Clin Oncol 1990;8:1664-1674.

40. Razek A, Perez CA, Tefft M, et al. Intergroup Ewing's Sarcoma Study: local control related to radiation dose, volume, and site of primary lesion in Ewing's sarcoma. Cancer 1980;46:516-521.

41. Rosen G, Caparros B, Nirenberg A, et al. Ewing's sarcoma: ten-year experience with adjuvant chemotherapy. Cancer 1981;47:2204-2213.

42. Marco, RA, Gentry JB, Rhines LD, et al. Ewing's sarcoma of the mobile spine. Spine 2005;30:769-773.

43. Talac R, Yaszemski MJ, Currier BL, et al. Relationship between surg ical margins and local recurrence in sarcomas of the spine. Clin Orthop 2002;397:127-132.

44. Stener B. Complete removal of vertebrae for extirpation of tumors:a 20-year experience. Clin Orthop 1989:72-82.

45. Tomita K, Kawahara N, Baba H, et al. Total en bloc spondylectomy: a new surgical technique for primary malignant vertebral tumors. Spine 1997;22:324-333.

46. Boriani S, Biagini R, De Iure F, et al. En bloc resections of bone tumors of the thoracolumbar spine. A p reliminary report on 29 patients. Spine 1996;21:1927-1931.

47. Tomita K, Kawahara N, Kobayashi T, et al. Surgical strategy for spinal metastases. Spine 2001;26:298-306.

48. Telles NC, Rabson AS, Pomeroy TC. Ewing's sarcoma: an autopsy study. Cancer 1978;41:2321-2329.

49. Brennan MF, Casper ES, Harrison LB, et al. The role of multimodality therapy in soft-tissue sarcoma. Ann Surg 1991;214:328-336.

50. Collin CF, Friedrich C, Godbold J, et al. Prognostic factors for local re cu r rence and survival in patients with localized extremity soft-tissue sarcoma. Semin Surg Oncol 1988;4:30-37.

51. Tepper JE, Suit HD. Radiation therapy alone for sarcoma of soft tissue. Cancer 1985;56:475-479.

52. Rock J, Kole M, Yin FF, et al. Radiosurgical treatment for Ewing's sarcoma of the lumbar spine. Spine 2002;27:E471-E475. 